\title{
IoT BASED TOLL BOOTH MANAGER
}

\author{
Somesh Pathak \\ Student, \\ Department of Electrical \\ Engineering, \\ K.K. Wagh Institute of Engineering \\ Education and Research, Nashik, \\ Maharashtra, India \\ Hrishikesh Kedar \\ Department of Electrical \\ Engineering, \\ K.K. Wagh Institute of Engineering \\ Education and Research, Nashik, \\ Maharashtra, India
}

\author{
Kartikay Bhat \\ student, \\ Department of Electrical \\ Engineering, \\ K.K. Wagh Institute of \\ Engineering Education and \\ Research, Nashik, \\ Maharashtra, India
}

\author{
Vinod Ahire \\ Student \\ Department of Electrical \\ Engineering, \\ K.K. Wagh Institute of \\ Engineering Education and \\ Research, Nashik, Maharashtra, \\ India
}

\begin{abstract}
There are thousands of vehicles on road these days and managing these multiple vehicles at a toll booth at the same time is a very difficult job to be done. At present, the manual toll system is very inefficient and very time-consuming. Due to this, there are traffic jams, fights, exchanges of words also. The system proposed is completely managed on the 'Internet of Things' concept based on RFID technology. The Internet server will store all the users ' required data and their card balance. When the car driver will arrive at the toll booth, the system at the toll booth will scan the card. The system then connects to the online server to check the validation of the card, if the card is valid and will be having sufficient funds then the particular amount will get deduced from the card. The system operates a motor to open the toll gate for a car to pass on deduction of the card balance. The entire system uses a microcontroller to achieve this purpose. The WiFi connection connects to the internet through which the system interacts for online verification. Additionally, all the data of the vehicles passed will get stored for later reference. Thus, the system automates the entire process of the toll booth and terminates the present process of the toll booth collection system.
\end{abstract}

Keywords-Internet of Things (IoT), Radio Frequency Identification (RFID), Toll Booth, Toll Collection, Web Server

\section{INTRODUCTION}

IoT, exactly what is IoT? The Internet of Things (IoT) refers to the network of internet-connected things or devices that are able to collect and transfer data over a wireless network. Now the question arrives that why it's here, because of ease of toll managing nowadays as the population is increasing so rapidly the number of vehicles is increasing too and managing this large number of vehicles by the current system is difficult. By using the old system there are many problems like due to the limited number of toll booths and slow collection process, the average waiting time per vehicle is very high. This results in losses worth thousands of crores of Rupees in terms of fuel wastage. This long wait time often results in drivers getting irritated resulting in verbal exchange and physical fights among people and the toll attendants. That's why this new IoT Based system is necessary for managing the toll booths.

This new system is the solution to the old system's problem, this new system works on Radio Frequency Identification (RFID) card technology, RFID cards provided to the users are scanned through RFID reader fixed at tollbooths in specific positions, and online transactions are carried out regarding the specific RFID card number of the users. By using of internet it creates transparency between users and toll booths and also it reduces the corruption rate, IoT provides real-time toll revenue collection data figures over cloud platforms which will beneficial to the government for monitoring the toll booth management. Ultimately the purpose of this project is to increase the efficiency of the toll booth system which contributes to becoming India a developed country.

\section{LITERATURE SURVEY}

An automatic toll collection system in the paper "Smart Toll Collection Based on IoT" shows the effective and prominent way to develop the system but it also showed that various methods are lacking by comparing with various other methods like Leach-C and NFC. Implementation of RFID technology 


\section{International Journal of Engineering Applied Sciences and Technology, 2021 Vol. 6, Issue 1, ISSN No. 2455-2143, Pages 437-440 \\ Published Online May 2021 in IJEAST (http://www.ijeast.com)}

eliminates other technology and makes the system more timeefficient. The survey done in the paper was on the frequency of $125 \mathrm{kHz}$ which shows us the path by which using and developing RFID antenna frequency for scanning the details of subjects vehicles from very less distance

The review was also done on the paper "Automated toll collection system using RFID" which enlightened us with various hardware components that could be used during developing our own system in a time-saving and efficient way. The survey done in the paper named turned out to be very helpful in developing an automatic toll collection system as we tried to use the best technology and choosing components in terms of reducing operating cost, time-saving, and flexibility.

\section{SCOPE OF PROJECT}

Whenever the concern is regarding the integration of the system, we think of having the following features -

a) Accuracy: The system should work with no errors whatsoever and should care accuratly diagnose.

b) Reliable and cost-effective: Our system is very reliable and our system does not require any additional software. Also, the hardware module used in the system is cost-efficient. Hence, our system is of low cost as compared with the existing system.

c) Efficiency: The system should work under all circumstances and should be efficient for a long life span.

d) Prerequisite Involved: As the system existing is not altered and the integration is done in the background. Therefore, no special training is required.

\section{EXISTING SYSTEM}

In the existing system, we have to manually enter the data and toll amount collection process from vehicle owners is also manual. This process requires more manpower and also a time-consuming process. This makes vehicle owners wait in a long queue which causes pollution and wastage of fuel. This process is very complicated as the receipt has also to be generated manually. Being a manual process, it involves more error generation. So, in order to make the system more accurate and less time-consuming the automation in the system is required.

\section{PROPOSED SYSTEM}

In this system, we have introduced an automatic toll collection process by using RFID technology and IoT. It is the simplest way of toll collecting process involving time-consuming and less manpower as compare with the existing system. A passive tag is used in this process, an RFID tag that does not contain any battery. The RFID tag has a useful life of twenty more at least. This size of it is small which makes it easy to carry. With the help of IoT data gets automatically stored on the web. It is very accurate and eliminates the drawback of the existing system.

\section{HARDWARE MODULES}

1. Arduino Uno: Arduino Uno used is an 8-Bit ATmega328P microcontroller. It is basically easy to use and easy to code. Arduino is connected with a computer attach at the toll booth. 2. Infrared Sensor: IR sensor or Infrared Sensor is an electronic device that senses the surrounding objects. It can measure heat as well as detects the motion of the object. It is used to sense the car when it arrives or departed the toll booth. 3. Transmitter: A transmitter is a device that sends signals in radio waves. It converts the Direct Current to Alternating Current to the desired frequency

4. WiFi Reader (EM18): WiFi reader is used to sharing information and transfer data through WiFi connections among various kinds of devices. It is basically an RFID reader whose purpose is to read RFID tags of a particular frequency of $125 \mathrm{kHz}$. After reading tags it sends signals to the microcontroller or PC

5. WiFi Router: The purpose of using a WiFi router is to connect a local network to another network or the internet.

6. Servo Motor: Servo motor basically runs on the PWM (Pulse Width Modulation) principle, which means angular rotation can be controlled by the duration of the pulse applied to its controller pin. Servo motor is used in the open and closing of toll gate at the desired angle.

7. LCD: LCD (Liquid Crystal Display) is a flat display commonly used in TVs, laptops, etc. Its purpose is to display informative messages such as card balance, if a card is valid or not.

\section{SOFTWARE MODULES}

1. Programming Language: $C$ Programming language is used. It is a general-purpose programming language that is extremely simple and flexible to use. It is the machineindependent language that is used to write various applications.

2. Arduino IDE: The Arduino Integrated Development Environment contains a text editor for writing codes. It is used in connecting to Arduino hardware to upload programs and communicate with them.

\section{METHODOLOGY}

1. IOT Based Toll Booth Manager is the automated process to carry out the toll collection and monitoring.

2. The vehicle driver having an RFID card arrives at the toll booth, the RFID reader will read the card number, and the microcontroller process the card information.

3. Microcontroller will check the validation of the card and if a card has sufficient balance.

4. Once the microcontroller checks the validation and the sufficient funds, the particular amount gets deducted from the card. The toll gate then gets open for the vehicle to pass.

5. The online server maintains the data sent by the microcontroller. MySQL database creates the database of user 
information where the information regarding the RFID card number, date, and time of entry in the toll will get stored.

6. Interaction between user and web is possible with the help of an HTML page.

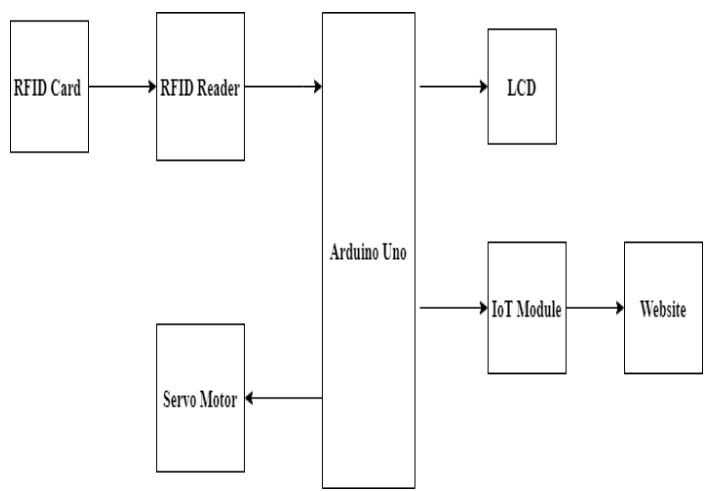

Fig. 1. Block Diagram showing hardware modules connected to Arduino Uno

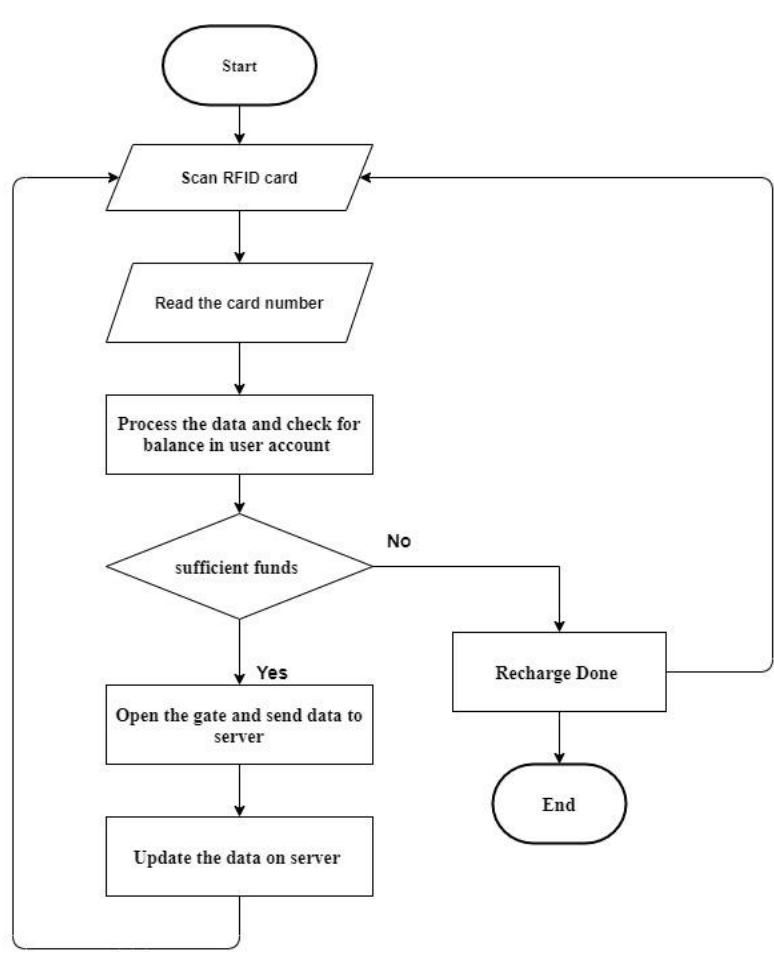

Fig. 2. Flowchart of the process involved in the system showing every possible scenario

\section{RESULT}

Following are the figures of the webpage and interfacing with Arduino Uno of various hardware as were discussed earlier.

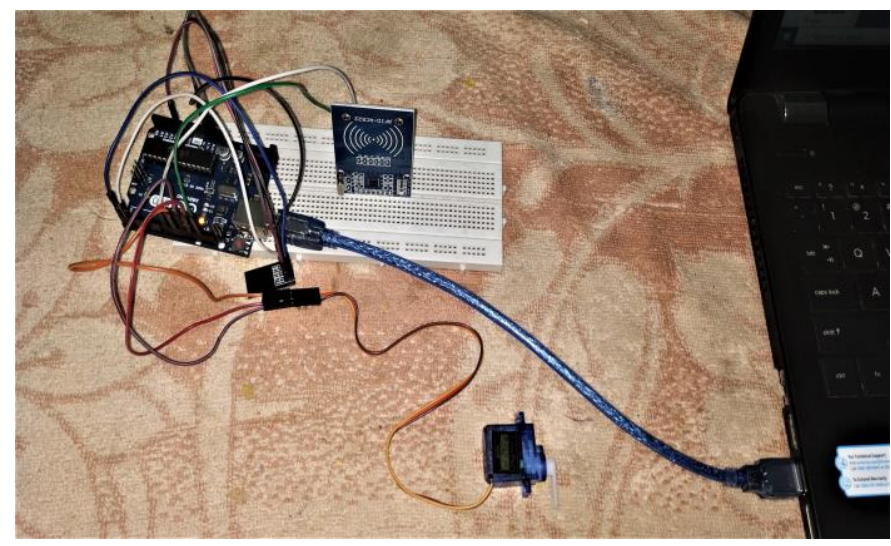

Fig. 3. Real-time implemention of Arduino Uno with other hardware modules

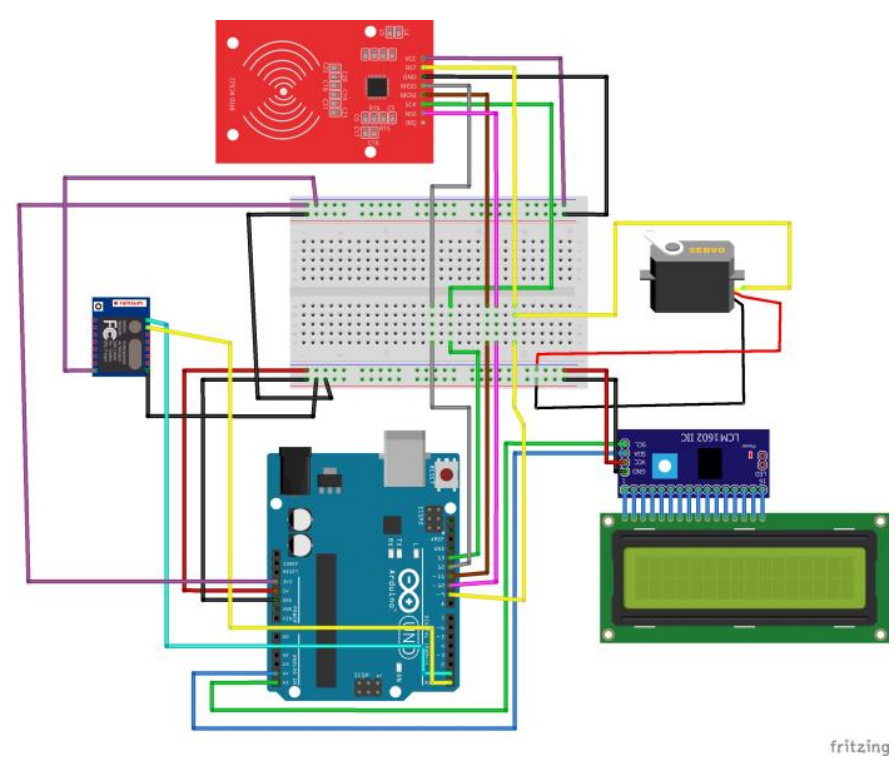

Fig. 4. Circuit diagram of the process involving all the components interfaced with Arduino Uno

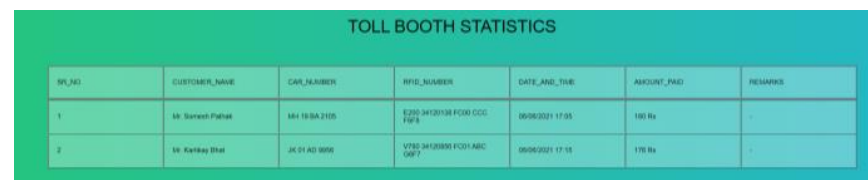

Fig. 5. Webpage showing the detalis of the RFID users 


\section{CONCLUSION}

RFID-based technology is a replacement for existing technology. It is the technology offering various features. Our system offers a highly reliable data collection system in a harsh environment. It is an efficient way of collect, manage and store information. It reduces all the existing problems faced by the people as it is a fully automated system. RFID technology provides greater automated tracking capability than existing technology. Thus, reduce manpower and improve inventory management, leading to low operational cost and increasing revenue generation.

\section{ACKNOWLEDGMENTS}

We would like to express our sincere gratitude towards our guide Prof. Rupali Ahire ma'am for her co-operation and encouragement which helped us in the completion of the project. During this process of learning and implementation, she guided us in every aspect. She helped and motivate us to propose research in this field and inspired us with her enthusiasm for research, her experience, and her lively character. Our appreciation also goes to the project members who helped with all their abilities.

\section{REFERENCES}

[1] Sridevi, Vasantha Pai, Rakesh Y," IoT Based Unmanned Toll Booth Monitoring System" International Journal of Innovative Research in Electrical, Electronics, Instrumentation and Control Engineering, (IJIREEICE), Volume 5, ISSUE 5, 2017.

[2] P. S. Hanwate, Ashlesh Mandke, Narin Meher," Smart Toll Collection System based on IoT", IJSTE International Journal of Science Technology \& Engineering, Volume 3, Issue 12, June 2017.

[3] Sudha M S, Yashodhre K, Snehil Sarkar, Spoorthy G, Shubham Khosla "IoT Based Toll Booth Management System”, International Journal of Progressive Research in Science and Engineering Volume-1, Issue-2, May-2020

[4] Pranoti Salunke, Poonam Malle, Kirti Datir, Jayshree Dukale "Automated Toll Collection System Using RFID" IOSR Journal of Computer Engineering (IOSR-JCE) eISSN: 2278-0661, p- ISSN: 2278-8727Volume 9, Issue 2 (Jan. - Feb. 2013)

[5] Allen Francis Antony, Anju P, Gautham Raj P,' Design of an Integrated Speed Tracking and Toll Management System for Express Highways", Proceedings of the IEEE 2017 International Conference on Computing Methodologies and Communication(ICCMC).

[6] Amit Hatekar, Nikita Kokal, Tarun Jeswani, Pratik Lalwani," RFID Based Automatic Toll Collection System using GSM", International Research Journal of Engineering and Technology (IRJET), Volume 03, Issue 04, Apr-2016.
[7] Rafiya Hossain, Moonmoon Ahmed, Md. Mozadded Alfasani, Hasan U. Zaman, "An Advanced Security System Integrated with RFID Based Automated Toll Collection System", 2018 IEEE Intelligent Vehicles Symposium (IV) Changshu, Suzhou, China, June 26-30, 2018.

[8] Etqad Khan, Dipesh Garg, Rajeev Tiwari and Shuchi Upadhyay, "Automated Toll Tax Collection System using Cloud Database", International Journal for Research in Applied Science \& Engineering Technology (IJRASET), Volume 3, Issue 2,2018

[9] Amol V Dhumane, Rajesh S. Prasad, Jayashree R. Prasad," An Optimal Routing Algorithm for Internet of Things Enabling Technologies", International Journal of Rough Sets and Data Analysis, Volume 4, Issue 3, JulySeptember 2017 